\title{
REFLEXIONES SOBRE LA Política LingüÍSTICA Peruana
}

\section{Inés Pozzi - Escot}

Recuento crítico de las políticas lingüísticas explícitas e implícitas habidas en el Perú en los últimos 25 años. Se analiza previamente tres conceptos esenciales: lengua nacional, lengua oficial y lengua estándar. Los enunciados explícitos sobre política lingüística provienen de documentos legales: constitución del79, leyes de educación y de oficialización del quechua (de alcance nacional y regional Inca), documentos de Política de Educación Bilingüe; publicaciones de reuniones académicas, y los trabajos de especialistas en la materia. Se hace notar que las preocupaciones de política lingüistica en el Perú han estado ligadas directamente a la problemática educativa antes que a las lenguas específicamente.

This article is a critical review of Peru's explicit linguistic politics in the last 25 years. It first analyzes three essential concepts: national language, official language and standard language. The explicit declarations about linguistic policy are found in legal documents: the Constitution of 1979, laws dealing with education and the officialization of Quechua (on a national level and for the Inca region), documents on Bilingual Education Policy, publications of academic meetings and the work of specialists. These documents show that the concern of linguistic policy in Peru has been directly related to educational matters rather than specifically to the languages. 
1.- En estos momentos, cuando se ha elegido un Congreso Constituyente para modificar la Constitución vigente o elaborar una nueva, parece de rigor una reflexión sobre la política lingüística peruana, explícita o implícita. Para concentrar nuestro análisis, creo conveniente fijarnos límites en el tiempo y lo haré dirigiendo mi atención a los últimos 25 años, desde la irrupción del gobiemo revolucionario del General Velasco a la fecha. Escojo este período porque ha sido el que abordó la cuestión lingüística con más decisión y realismo, fuera de que nos planteó las interrogantes más profundas sobre nuestra identidad.

2.- Antes de seguir adelante con este análisis de la política lingüística de las dos últimas décadas, debemos detenernos para una clarificación de términos que se hace imprescindible. Los que me preocupan fundamentalmente son: lengua nacional, lengua oficial y lengua estándar.

Lengua nacional y lengua oficial tienen en común que no dependen de variables lingüísticas sino de variables de otro orden: políticas, sociales, etc. Según Paul L. Garvin, la denominación de lengua nacional abarca dos sentidos: el primero equivalente a una lengua que "sirve a todo el territorio de una nación en lugar de hacerlo sólo para una región o subdivisión étnica", y el segundo, el de "una lengua (que) funciona como símbolo nacional" (Garvin 1973:25). Si nos basamos en el primer sentido, el castellano es lengua nacional en el Perú indudablemente, pero, en cuanto al segundo sentido, habría algún problema puesto que el Perú no es un país cultural o lingüísticamente uniforme pese a que nuestra convivencia con el castellano y la cultura hispánica dura varios siglos. El castellano es siempre para algunos sectores del país, la lengua que vino con el invasor y que no puede representarnos como sí lo pueden hacer las lenguas ancestrales mayores, el quechua o el aimara. En todo caso, el Perú se ha librado de la dolorosa tarea de elegir una lengua nacional como ha ocurrido con tantos pueblos que se independizaron del yugo colonial. Nuestra gesta emancipadora no cuestionó la validez del castellano como lengua representativa del nuevo país. Tuvimos la suerte que la lengua que heredábamos como lengua nacional era una lengua de ámbito mundial que permitía, con ciertas limitaciones, la comunicación interna y externa.

El mismo Garvin aclara que el criterio de definición para una lengua oficial "es el reconocimiento oficial por una autoridad gubernamental" (Ibid:25). Por lo tanto, la oficialización de una lengua, en principio, no está subordinada a su condición lingüística; vale decir, así ha sido normada mediante la elaboración de gramáticas, diccionarios, etc. Sin embargo, como lo hace notar Garvin, 
por lo general, las lenguas oficializadas o poseen ya normas de pronunciación, gramaticales, de escritura y estilísticas explícitas o éstas están en trance de ser fijadas. Recordemos que a las lenguas internacionales como el castellano, el inglés y el francés, para citar ejemplos conocidos, les ha tomado siglos uniformar sus usos en un código estándar. En el prólogo de una edición modernizada, en puntuación y ortografía, de la Nueva Crónica y Buen Gobierno de Huamán Poma, se señala, en relación con la época en que la obra fue escrita, que "la ortografía de esos tiempos era vacilante y variable" (1990:14). Sin embargo, el castellano era la lengua oficial de estos reinos. Es cierto que las nuevas lenguas que ingresan a la esfera política en el mundo de hoy, con la escritura tan difundida y la hegemonía de los medios de comunicación masiva, tienen que ser objeto de acción deliberada-de tratamiento-para ponerlas en capacidad de uso en plazos relativamente cortos. Así surge la planificación lingüística, de la cual el mundo moderno nos da ejemplos impresionantes.

La oficialización puede tener sus límites. Una lengua puedeser oficializada para todo el país o para una parte deél solamente. En consecuencia, puededarse una doble oficialización por zonas, como ocurre en España, en las comunidades autónomas. Tomemos el caso de Cataluña donde el catalán es oficial a la par que el castellano; o sea, que se trata de una co-oficialidad. La Ley de Normalización Lingüística de Cataluña señala que el catalán es la lengua específica del gobierno y la administración local de Cataluña aunque los habitantes de Cataluña tienen el derecho de ser atendidos en cualquiera delas dos lenguas oficiales. En cuanto al campo educativo, la Ley citada establece que el catalán es la lengua específica de la educación en todos los niveles como lengua instrumental, fuera de ser lengua enseñada como asignatura. (1)

En el caso de España y Cataluña, la oficialización está marcada en términos del espacio geográfico-político así como en los rubros en los cuales rige: gobierno y administración local, educación, etc. A nivel general, no hay una definición única de lo que implica declarar oficial a una lengua. Esto tiene que ser establecido por leyes complementarias.

Ya hemos adelantado algunas ideas sobre la estandarización al tratar sobre la oficialización de lenguas. La literatura sobre estandarización y lengua estándares amplia e incide en el esfuerzo por eliminar diferencias ahí donde hay variedades diversas de una misma lengua, a fin de lograr cierta homogeneidad. Se trata de privilegiar una variedad existente entre otras, o de crear un sistema artificial concebido para la escritura, por ejemplo, y que nadie usa en el habla, como es el caso del hausa estándar (Wolff: 1991,21) en el Africa occidental. 
Fishman sostiene que el proceso de estandarización incluye dos pasos: la fijación del modelo por imitar y la promoción de este modelo (1968:761). Por "fijación" ha de entenderse la codificación; vale decir, la explicitación de las normas de pronunciación, de gramática, de escritura, en manuales, gramáticas normativas y diccionarios. Generalmente, alguna agencia con autoridad-ya sea el Ministerio de Educación o una Academia de la Lengua-seencarga de fijar las normas y su promoción corresponde a las escuelas, los medios de comunicación de masas y a los escritores representativos.

3.- Volviendo a nuestro tema, ¿qué habia como política lingüistica en la década del 60 que pudiera presagiar ese fermento extraordinario de la década del 70?

En 1971, Donald F. Solá, lingüista estadounidense, en una ponencia sustentada en el Simposio de Puerto Rico del PILEI (Programa Interamericano de Lingüística y Enseñanza de Idiomas) y titulada Típologia de la Política Linguística, comentaba que en el Perú que él visitó en 1959, se desarrollaba en la selva, un programa de educación bilingüe, por el cual se podría decir que "el gobierno peruano tenía una política explícita de educación bilingüe para las escuelas selváticas" en las que se alfabetizaba a los niños en su propia lengua antes de iniciar la enseñanza del castellano, pero en la sierra el gobierno "parecía seguir una política completamente opuesta a la que se seguía en la selva" (Solá 1974:6), inhibiendo el uso de las lenguas nativas tanto para la educación de los niños monolingües de lengua vernácula como para la educación de adultos analfabetos. Lo extraordinario era que las condiciones de monolingüísmo en vernáculo se manifestaban en forma igualmente impresionante en ambas regiones. Esta constatación llevó a Solá a calificar de "inconsistente" a esta política contradictoria y a postular como una categoría de su tipología, la bipolaridad: consistenteinconsistente.

En otro párrafo de su ponencia, Solá anotó que después de haberse desarrollado "un breve y muy localizado proyecto experimental en la sierra, el gobiemo peruano produjo una declaración al efecto de que ell quechua se debería emplear en las escuelas cuando fuera necesario", lo que podría aceptarse como una política positiva salvo que, señalaba, su falta de precisión, la anulaba. Agregó Solá que la reacción del personal del Ministerio de Educación fue reinterpretar "cuando fuera necesario" para significar "lo menos posible"; la respuesta natural de cualquier burocracia que esté confrontada con un problema técnico muy difícil, sin los fondos para trabajar en ello. Así que, "lo menos posible" fue la política implícita del gobiemo, totalmente contraria a la política 
explícita que sí tenía ciertos méritos, pero por la falta de detalles clarificadores no podía tener ningún significado real (bid: 7 ). En consecuencia, según este testimonio de un lingüista cuyo interés profesional radicaba en el quechua, inconsistencia y vaguedad son las características de la política lingüística de la década de 1960 a 1969.

Un evento importante sirvió de estímulo intelectual y acicate a la década del 70 en términos de política lingüística: la Mesa Redonda sobre el monolingüismo quechua y aimara y la educación en el Perí, en 1963, por un grupo de educadores, antropólogos y lingüistas en la Casa de la Cultura del Perú, presidida entonces por José María Arguedas. El país estaba recibiendo en esos años el influjode una nueva hornada de científicos sociales, en especial, de lingüistas cuyos aportes habían de marcar las décadas sucesivas. El gran vocero de esa corriente fue Alberto Escobar, a quien correspondió sustentar la primera ponencia titulada: La Linguística y el Problema de la Población Monolingüe Quechua y Aymara, cuya presentación y debate ocuparon la primera sesión. Al presentar al ponente, José María Arguedas dijo: "Cedemos la palabra al Dr. Alberto Escobar, que va a tratar sobre el primer tema que es la alfabetización y el establecimiento de una política lingüística peruana". Subrayo estas tres últimas palabras porque indican la intención de la ponencia: delinear una política linguística peruana.

La ponencia de Escobar y el debate que suscitó son de importancia ya que destacan los problemas que debían ser materia de decisión; vale decir, de política lingüística. Enumeremos algunos de los problemas que lo preocupaban: 1.-El Perú es un país plurilingüe con una alta proporción de hablantes de lengua vernácula que desconocen la lengua oficial o la manejan apenas. 2.-No existe, por ende, una lengua común que permita la comunicación en todo el territorio. 3.-Se confunde alfabetización con castellanización como si fueran un solo proceso y así se hacen fracasar ambas acciones. 4.-Se ignora que la enseñanza del castellano a los vernáculo hablantes exige textos y metodología específicos, pues la enseñanza de una lengua materna no es equivalente a la enseñanza de una segunda lengua. 5.-La educación oficial cierra los ojos a la realidad e impone una sola lengua de enseñanza como si todos los educandos fuesen hispanohablantes. 6.-Tanto el grupo mestizo como los quechuahablantes adultos, campesinos o no, por prejuicios diversos, se oponen al uso de las lenguas aborígenes en la escuela.

La propuesta de Escobar es comenzar la educación de los educandos de lengua vernácula en su lengua materna para luego introducir el aprendizaje del castellano de manera sistemática. En esta primera fase en lengua materna, se ha 
de cumplir la alfabetización (lectura y escritura). Escobar es muy cuidadoso de esclarecer en su propuesta que no se trata de desplazar las lenguas aborígenes con la enseñanza del castellano sino que éstas "coexistiendo con la lengua general que en el Perú sería el español, mantendrían su vigor en ambientes geográficos o sociales más reducidos " (Ibid:28). La tesis de Escobar sobrepasa los linderos del debate entre hispanistas e indianistas y avizora un Perú bilingüe en ciertas zonas y para ciertas clases sociales.

En la discusión que se suscitó al finalizar su ponencia, Escobar insistió: "...Lo que nosotros deseamos que.tenga un cambio, es la política del Ministerio en la apreciación del problema de la escuela y el problema de las lenguas aborígenes; y esa política, tal como está hoy día planteada, está planteada en términos que equivalen a suponer que el Perú es un país monolingüe (mientras que la observación de la realidad nos descubre que el país es plurilingüe) y omite que el Perú es lo que se llama en términos corrientes un país subdesarrollado, y que la consideración del problema lingüístico es básica para combatir el subdesarrollo..." (Ibid:36). La relación entre desarrollo y política lingüística está aquí enunciada.

Fuera del tratamiento de las lenguas aborígenes y del castellano en la educación formal, algunos asistentes a la Mesa Redonda, entre ellos el Dr. John Murra, se preocuparon por destacar que concernía a una política lingüística peruana tratar sobre el "futuro de los idiomas aborígenes en una dimensión mayor que la de la alfabetización en su nivel elemental". Esta línea de discusión lleva al Dr. Oscar Núñez del Prado, ya dentro de la discusión de la segunda ponencia sobre experiencias de alfabetizaciôn con adultos y con niños en Cuyochico, a plantear la pregunta: "...ipodríamos conseguir en el Perú que el quechua y el aymara tengan la categoría de idiomas oficiales, también, paralelamente al castellano?" (Ibid:74). Murra contesta que depende de lo que los peruanos quieran hacer, pero que está seguro que el Dr. Núñez del Prado "muy bien puede imaginarse un Perú que no sea sólo multicultural sino que tenga varios idiomas oficiales". Recordemos que ese diálogo vibrante se realizó en 1963 y que Arguedas informó en ese momento que esa misma noché un diputado cusqueño presentaba un proyecto de ley para hacer al quechua y al aymara lenguas oficiales así como para lograr que los funcionarios que tuvieran que tratar con público monolingüe fuesen quechuahablantes. Ahí parece haber un error de transcripción o de concepción porque en nada ayudaría a un monolingüe aymara el que el funcionario fuese bilingüe en castellano y quechua, pero valga la intención de bilingüismo. La Mesa Redonda plantea así dos temas centrales a la política lingüística peruana: la oficialización delenguas vernáculas $y$ el fomento del bilingüismo. 
En la tercera y última sesión uno de los temas discutidos es el de la integración como solución a esa fragmentación social, a esa incomunicación, a ese disloque a que varios oradores se han referido. El Dr. Murra pide que la integración no sea entendida como algo unilateral, sino que se vean los aportes del mundo andino del cual la civilización occidental tiene mucho que aprender. Carlos Cueto avanza el análisis de esta idea hacia lo que hoy llamamos la interculturalidad al proclamar: "El Perú que nosotros queremos tiene que resultar de una integración multilateral, ya no solo bilateral, porque el Perú es un país ya no dicotómico culturalmentesino que culturalmente es multicotómico; tiene queser una integración múltiple..."(Ibid:120). Queda claro también quelas soluciones al problema-Perú tienen que ser interdisciplinarias.

5.-Los debates de la Mesa Redonda de 1963 habían mostrado que la política educativa y la política lingüística tenían que ir de la mano en un país con las características sociolingüísticas del nuestro; estas políticas debian estar enraizadas además en proyectos de desarrollo que modificasen el contexto de dependencia interna y externa. Por extraordinaria coincidencia, al producirse la revolución política de 1968, el gobiemo revolucionario llama al Ministerio de Educación a algunos de los participantes de la Mesa Redonda de 1963, para ocupar puestos claves y se presenta una oportunidad nunca habida para incorporar algunas de las ideas aportadas. En el Primer Seminario Nacional de Educación Bilinguie, realizado en enero de 1972, en un ambiente de gran agitación ideológica, un grupo de asistentes pide la oficialización de todas las lenguas autóctonas habladas en el Perú, sin lograr consenso. Un primer producto de este período que plasma ideas bullentes, es la Ley General de Educación 19326, de 1972, especialmente en los artículos 12, 98, 246 y 301.

El texto del articulo $12^{2}$ es: "La educación considerará en todas sus acciones la existencia en el país de diversas lenguas que son medios de comunicación y expresión de cultura, y velará por su preservación y desarrollo. La castellanización de toda la población se hará respetando la personalidad cultural de los diversos grupos que conforman la sociedad nacional y utilizando sus lenguas como vehículo de educación".

Aquí se reconoce el multilingüismo peruano y la diversidad cultural y se afirma la voluntad del Estado de respetar esta diversidad y contribuir al desarrollo de las lenguas. (Mi subrayado). Se postula con este "desarrollo de las lenguas" su adecuación para un uso moderno de ellas, ampliando su léxico, por ejemplo, con terminologías técnicas. La castellanización se distingue de la hispanización, encuadrándola como enseñanza de un segundo idioma a educandos con una cultura propia que debe ser valorizada. 
El artículo $98^{\circ}$ incide en la visión global dentro de la cual tienen que ordenarse, las lenguas vernáculas como lengua materna de los educandos, el castellano como segunda lengua aprendida para lograr la comunicación interna mediante una lengua común que funcione como lengua nacional, y las lenguas extranjeras como soportes de la información científica y tecnológica, y la comunicación externa, a nivel mundial. Una vez más se insiste en la defensa de la "personalidad cultural" del educando para evitar el efecto destructivo de los modelos de conducta y pensamiento foráneos que penetran a través del aprendizaje de lenguas extranjeras. La defensa de las lenguas y culturas que nos nutren y el fomento de su reconocimiento y respeto fue un eje central de la política lingüistica, expresada en la Ley 19326 de 1972 . El texto del artículo $98^{\circ}$ es el siguiente:

"El aprendizaje de los idiomas extranjeros en los centros educativos se realizará de modo que no constituya factor de perturbación y alienación de los educandos ni de imposición cultural. Puede iniciarse a partír del primer ciclo de acuerdo a la metodología de enseñanza de segunda lengua.

Se fomentará el aprendizaje de las lenguas vernáculas. Los centros educativos darán facilidades para el conocimiento de dichos idiomas y de su influencia en la lengua y cultura nacionales".

El artículo $246^{\circ}$ se ocupa de la utilización de la lengua vernácula para facilitar la alfabetización y castellanización, con lo cual seelimina la abominable proscripción de las lenguas vernáculas de las escuelas y de los procesos de enseñanza-aprendizaje. En el artículo $301^{\circ}$ se considera obligatorio el aprendizaje de una lengua vernácula en la formación magisterial, a fin de evitar la incomunicación verbal tan frecuente entre maestros y alumnos y al mismo tiempo coṇtribuir a elevar el estatus de estas lenguas vernáculas.

6.-El año 1972 es también histórico por la aparición de la primera Política Nacional de Educación Bilinguie. Nace como un producto depurado por la meditación del caudal de ideas y tendencias vertidas en el "Primer Seminario Nacional de Educación Bilingüe" en enero de ese año. Su importancią no ha disminuido con el tiempo, ni ha dejado de tener vigencia su llamado de atención sobre el complejo entroncamiento de lo linguiístico en lo socio-económico, a tal punto que señala como primer objetivo de la educación bilingüe lo siguiente: "Propiciar en las comunidades de lenguas vernáculas, la interpretación crítica de su realidad socio-económica para su participación espontánea, creadora y consciente en el proceso de cambio estructural orientado hacia la 
eliminación de los mecanismos de dependencia y dominación" (Ministerio de Educación 1972:10). Esta idea se reitera en los Lineamientos de Política: "...Por lo tanto, la alfabetización y la castellanización, entendidas como un proceso pedagógico al margen del enfoque socio-económico, son improductivas e indeseables."(Ibid:9). Lástima que aún no hemos captado el verdadero sentido de esta afirmación y a menudo se enfoca la educación, en cualquiera de sus modalidades, como algo aislado de las necesidades vitales de todo orden, sin comprender que educar es educar en la vida para la vida, que no se educa a un hombre si no se le enseña a participar en el proceso productivo y mejorar sus condiciones de existencia y las de su habitat.

7.-La idea de la oficialización de las lenguas se concreta por primera vez en 1975 con el Decreto Ley N² 21156 de oficialización del quechua que reconoce al quechua como lengua oficial del Perú, junto al castellano.

El decreto oficializa a todas las variedades del quechua y no a una sola, con lo cual se gana la batalla del reconocimiento público de la equiparidad de todas las variedades del quechua. El Instituto de Estudios Peruanos en un detallado análisis que dedicó a este decreto lo califica "entre las medidas más audaces y creativas generadas en la historia social del continente "(Escobar y otros, 1975:64), y lo comprende dentro de las medidas de reestructuración de las relaciones de poder, emprendidas por el gobierno revolucionario de 1968, con el fin de reorientar a la sociedad peruana "hacia un modelo igualitario que acabe con los desequilibrios internos y busque conformar una nación social y culturalmente integrada en todos sus niveles" (lbid:63). Creo que es importante anotar que los autores de Perí, ¿país bilingüe? ven la oficialización del quechua como un desafío que consiste "en convertir orgánica e institucionalmente al Perú en una sociedad bilingüe", con nuevas bases de interacción entre los 'gruposdominantes y los dominados. Reiteremos: enel análisis de la oficialización del quechua hecha en el libro que venimos citando, no se trata de una acción de política lingüística aislada. Retomando el eco de lo que ya señaláramos en la Política Nacional de Educación Bilingüe de 1972, la oficialización del quechua y su implementación se ven exitosas si van acompañadas de cambios profundos en el plano económico y de poder político, si se entienden como parte de transformación de la sociedad peruana en su conjunto.

El decreto no pudo ser implementado, salvo en un aspecto poco trascendente: la publicación de las gramáticas y diccionarios correspondientes a las principales variedades del quechua. El giro político que se produjo a nivel del país abortó esta reforma y nos dejó con la incógnita de lo que pudo haber sido. Pienso, sin embargo, que hubo errores de concepción en el Decreto, pese a sus 
aciertos e indiscutibles buenas intenciones. De un lado, que debíó ser una oficialización restringida, para aquellas zonas que censalmente habían resultado con al tos números de monolingües de quechua y/o de bilingües de quechua y castellano. El gradualismo ha probado ser en la mayoría de los casos, más manejable que la imposición arbitraria. El Decreto establecía la enseñanza obligatoria del quechua a partir del siguiente año escolar, 1976, en todos los niveles educativos. ¿Qué pasaría con los monolingủes de lengua vernácula que no eran quechuahablantes? Me parece que el aspecto de la enseñanza obligatoria del quechua fue el que mayor reacción negativa produjo en la población porque el Decreto no había estado precedido por una etapa de motivación y sensibilización de la población hispanohablante, para quienes el aprendizaje del quechua no ofrecía ningún atractivo. Se podía entender que el Estado prestara servicios en ambas lenguas, quechua y castellano, en la administración pública y en el Poder Judicial, pero de ahía que toda la población de la República se viese obligada a aprender una lengua que, a su juicio, no se necesitaba y que no agregaba prestigio a los hablantes, había un largo trecho. ¿Por qué no pensar en requisitos de bilingüismo quechua-castellano para nombramientos en la burocracia estatal que sirvieran como estímulo y acicate? Si los que concibieron este Decreto hubieran podido pensar en una co-oficialidad restringida tanto en el plano geográfico-político como en el de las funciones estatales a las que se remitía, el Decreto hubiera tenido perspectivas de éxito. Tal como fue concebido, sus posibilidades fueron nulas y nunca fue aplicado.

8.-La planificación linguiística posterior está expresada en dos artículos de la Constitución de 1979: el $35^{\circ}$ y el $83^{\circ}$. El artículo $35^{\circ}$ establece:

"El Estado promueve el estudio y conocimiento de las lenguas aborígenes. Garantiza el derecho de las comunidades quechua, aymara y demás comunidades nativas a recibir educación primaria también en su propio idioma o lengua." (2)

En este artículo, hubiera sido de desear una redacción como la de la Ley de Educación de 1972 en la que se pide "preservar y desarrollar" las lenguas aborígenes, tareas esenciales que se involucran una a otra. Para preservar, hay que desarrollar, a fin de que las lenguas que son entes vivos, no se conviertan en vehículos ineficientes cuyos dominios de uso se restringen cada vez más. El "estudio y conocimiento" de las lenguas oborígenes que promueve la Constitución de 1979 no basta para reducir los riesgos de desplazamiento lingüístico sustitución de una lengua por otra- que aguardan a las lenguas que no se modernizan y que están en situación de subordinación en relación a otra u otras, manejadas por grupos de poder. 
La segunda parte del artículo $35^{\circ}$ de la Constitución de 1979 se refiere al uso de las lenguas vernáculas en la educación primaria solamente. ¿Y la educación inicial, y los otros niveles? Sorprende la modestia conceptual con que los legisladores han abordado la cuestión de las lenguas autóctonas en la educación. Volvamos al ejemplo de España y de Cataluña. Después de haber sido una lengua prohibida en calles, escuelas y todo lugar público en 1939, actualmente el catalán es la lengua de la educación en todos los niveles educativos, fuera de ser lengua enseñada como asignatura (New Language Planning Newsletter, Vol.6, No 3: p.3). Cataluna es un modelo de lo que la voluntad popular puede lograr si se decide por la lealtad lingüística.

Las "wawa wasi" y "wawa uta" creadas en zona quechua y zona aymara respectivamente, han sido acusadas de desconocer la educación bilingüe e imponer un régimen desumersión en castellano, pero no hay asidero legal para exigir lo contrario. Sin embargo, las cifras de educandos involucrados son considerables. En cuanto a la educación secundaria de la cual se han olvidado los legisladores también en 1979, la Dirección General de Educación Bilingüe del Ministerio de Educación publicó en 1989 un cuadro sobre la atención que presta a los grupos vernáculohablantes, en el cual se incluían 19 centros educativos bilingües de secundaria, dos en zona Andina y 17 en la Amazonía. ¿Por qué quedan esos centros sin respaldo legal en la Constitución? Evidentemente quelas cifras dadas por la Dirección General de Educación Bilingüe sobre educación secundaria bilingüe son muy exiguas. ¿A qué obedece eso?

Al respecto, al examinar el caso boliviano, el lingüista Pedro Plaza se pregunta si el reducir la utilización de las lenguas aborígenes a la escuela primaria, que representaría la aplicación del modelo de transición de la educación bilingüe, no es una de las maneras de abogar por la continuidad de la diglosia en nuestras sociedades multiétnicas y multilingües. Sostiene Plaza (1989:56):

"La educación bilingüe, para ser consecuente con sus propósitos, no tendría que estar limitada a la escuela primaria sino que debería extenderse a la secundaria e incluso a la universidad". Dada la ceguera existente sobre nuestra realidad nacional, no sorprende que este interesante punto no asome en la plenitud de sus implicancias en la discusión de los principales comentaristas peruanos de la Constitución de 1979. Los tratadistas, Marcial Rubio y Enrique Bernales, expresan con razón al abordar este artículo que "La Constitución no ha tratado con la debida profundidad, mesura y respeto esta cuestión de las lenguas o idiomas y ha sancionado una fórmula en laque subyaceel paternalismo 
y aquello que Salazar Bondy adecuadamente calificó como cultura de la dominación" (1983:156).

Otro aspecto importante que impacta en este artículo es que la referencia a la educación en el propio idioma aparece casi como una cuña, un agregado. El Estado garantiza el derecho a una educación primaria en lengua materna "también". Pero, ¿qué quiere decir eso en términos prácticos? ¿Se hará la educación para los vernáculohablantes simultáneamente en castellano y en la lengua ancestral, o será cuestión de elegir una u otra? Según este artículo, el Programa de Educación Indígena del Alto Napo que se hace enteramente en lengua vernácula, con el castellano como asignatura, estaría contraviniendo a la Constitución. Además, el Estado no garantiza proveer a los hablantes de lenguas vernáculas los medios para que una educación bilingüe se materialice. La realidad nos muestra que, en 1990, sólo un $8 \%$ de los escolares vernáculohablantesque deberían recibir educación bilingüeas istieron a escuelas de ese tipo.

Es de notar que el artículo $35^{\circ}$ utiliza el término "comunidades" para referirse al pueblo quechua y al aymara. Presume que los legisladores se encontraron "sin palabras" para designar a los hablantes quechuas o aymaras como grupo, dada la variedad de situaciones en que se encuentran. La palabra "nacionalidad" o "nacionalidades" aparece más y más en declaraciones públicas y escritos en nuestro país. Por ejemplo, un presidente de una asamblea regional hizo hace poco una evocación de la "nacionalidad quechua" en declaraciones aparecidas en un eminente diario capitalino. Una publicación de febrero de 1992, titulada Interculturalidad. Un desafio, afirma en relación a la subestimación colectiva de un grupo cultural: "el caso extremo de este fenómeno dentro de la Selva Amazónica son los llamados "nativos invisibles", descendientes de nacionalidades fuertes en el pasado, que actualmente habitan en los pueblos jóvenes de las grandes ciudades e intentan ocultar su idioma, sus apellidos y todas sus manifestaciones culturales (Heise etal: 19, mi subrayado). En Ecuador y Bolivia existe el uso frecuente del término "nacionalidades" referido a los grupos autóctonos. En el Ecuador la utilización del término "nacionalidades", refrendado por, la creación de organizaciones tales como la Confederación de Nacionalidades Indígenas del Ecuador, CONAIE, implica la determinación que se reconozca al país como Estado multinacional (Moya, 1989: 120-121). Sostiene Moya: "Los reclamos sobre la tierra y la territorialidad, el derecho a las lenguas y culturas propias, a la historia y modo de organizarse socialmente, van a constituir los rasgos de una propuesta política central: la autodefinición de estos pueblos como nacionalidades". 
En el Perú el uso caḍa vez más amplio del tẻrmino en medios de comunicación masiva, entre lingüistas y educadores ligados a la educación indígena, y entre científicos sociales interesados por aspectos diversos de nuestras micro y macro etnias, debería provocar la reflexión entre los juristas porque atañe al modelo societal. ¿Somos un Estado uninacional o multinacional? No hay indicios de esta preocupación ni en el texto ni en los comentarios a la Constitución de 1979.

El artículo $83^{\circ}$ de la Constitución de 1979 tiene la siguiente redacción:

"El castellano es el idioma oficial de la República. También son de uso oficial el quechua y el aymara en las zonas y la forma que la ley establece. Las demás lenguas aborígenes integran asimismo el patrimonio cultural de la nación," ${ }^{(3)}$

En este artículo se establece una jerarquía de tres niveles compuestos por la lengua oficial, el castellano, en primer término; las lenguas de uso oficial, restringidas al quechua y al aymara en las zonas y la forma que una ley por venir establezca; en segundo término y, por último, las demás lenguas aborigenes, para las cuales no se prevé ningún carácter oficial, salvo el de formar parte del patrimonio cultural de la nación.

El Dr. Enrique Chirinos Soto, integrante de la Asamblea Constituyente que elaboró la Constitución de 1979, incluye en su libro de divulgación, La nueva Constitución al alcance de todos, el artículo 3 de la Constitución Española de 1978, cuyo tenor es el siguiente:

1.-El castellano es la lengua española oficial del Estado. Todos los españoles tienen el deber de conocerla y el derecho de usarla.

2.-Las demás lenguas españolas serăn también oficiales en las respectivas Comunidades Autónomas de acuerdo con sus Estatutos.

3.-La riqueza de las distintas modalidades lingüísticas de España es un patrimonio cultural que será objeto de especial respeto y protección."

La analogía con el artículo $83^{\circ}$ de la Constitución peruana es evidente. ¿Acertaron los legisladores al establecer esta jerarquización? ¿Por quéllamaron al castellano "lengua oficial" y al quechua y aymara "lenguas de uso oficial"? La ley que debía convertir al quechua y al aymara en lenguas de "uso oficial" nunca 
fue promulgada. Recién al cumplirse con la regionalización establecida en la Constitución, la Región Inca que comprende tres departamentos -Cuzco, Apurímac y Madre de Dios-con alto número de vernáculohablantes, ha dado una ley de oficialización del quechua el 12 de febrero de 1991, lo que es muy laudable pues to que el camino propicio para la preservación y desarrollo de las lenguas autóctonas es el de la co-oficialidad en las zonas donde las lenguas indígenas coexisten con el castellano. Desgraciadamente, en dos de los 7 artículos de la ley regional de oficialización del quechua se han introducido decisiones sobre asuntos controvertidos, tales como imponer el uso del alfabeto quechua prescrito por la Academia Mayor de la Lengua Quechua cuando ya existe la Resolución Ministerial NN 1218-85-ED del 18 de noviembre de 1985 que oficializa el alfabeto trivocálico, aprobado en el Primer Taller de Escritura en Quechua y Aymara, realizado en 1983, en Lima, con nutrida representación de instituciones y hablantes, incluyendo un delegado de la academia cuzqueña. Otro aspecto cuestionable de la ley regional aparece en el artículo $5^{\circ}$, en el que se establece la sustitución de "los vocablos castellanos Inca y Cusco con los nombres quechuas Inka y Qosqo en los documentos del Gobierno Regional y de todas las demás instituciones públicas y privadas de la Región Inka", con lo cual la Región Inca se olvida de un principio elemental: cuando se escribe en castellano, se siguen las reglas de la ortografía castellana; cuando se escribe en quechua, se siguen las reglas de la ortografía quechua. ¿Por qué escribir "Inka" en un texto en castellano?

Regional:

Veamos el texto de los 4 primeros artículos de esta importante Ley

"Artículo $1^{\circ}$ Declarar al Idioma Quechua como lengua oficial de la Región Inka, por ser de uso oficial en las zonas y la forma que la ley establece según el artículo $83^{\circ}$ de la Constitución Política del Perú y porque es idioma oficial del Perú, por disposición del Decreto-Ley № 21156.

Artículo $2^{2}$ Disponer la obligatoriedad de la educación bilingüe intercultural Quechua-Castellano para todos los educandos vernáculo-hablantes maternos, en los niveles de educación inicial y primaria de la Región Inka.

Artículo $3^{\circ}$ Disponer la enseñanza obligatoria del Idioma Quechua en todos los niveles y modalidades del servicio educativo del ámbito de la Región Inka.

Artículo $4^{2}$ Disponer que la enseñanza del idioma Quechua se haga en base a las grafías oficiales aprobadas por la Academia Mayor de la Lengua 
Quechua, recomendándose la escritura en quechua de los nombres de las calles, pueblos, comunidades, ciudades, apellidos, accidentes geográficos y fenómenos naturales y su uso en todos los medios de comunicación social.

La Ley Regional declara que se fundamenta en el Decreto-Ley N221156, de oficialización del quechua a nivel nacional, aprobado en mayo de 1975, aunque ese Decreto-Ley no se aplicó jamás porque, poco después de su aprobación, se produjo un cambio de gobernantes y de orientación de la política estatal. Verdad es también que nunca fue derogado explícitamente.

La Ley Regional va más allá de la Constitución de 1979 al establecer la obligatoriedad de la educación bilingủe intercultural en la Región Inca aún en el nivel inicial. Olvida nuevamente el nivel de secundaria y el superior, con lo cual se ubica en el modelo de transición: educar en lengua materna al comienzo de la escolaridad para lograr la más rápida transferencia al castellano. La enseñanza del quechua como asignatura se convierte en una obligación que afecta a todos los niveles del sistema educativo en pos de un bilingüismo individual quechua-castellano y posiblemente castellano-quechua si los alumnos son hispanohablantes. Esta iniciativa es de enorme importancia pues no se ha intentado nunca en esa escala en el país. Para que triunfen tanto esta disposición como la referida a la educación bilingüe intercultural obligatoria se necesitan materiales y maestros formados y/o capacitados, a fin de que procedan con eficiencia y comprensión en su turea. Otra necesidad es la labor de difusión y orientación del público para que hagan suyos los objetivos de bilingüismo y preservación y desarrollo de la lenguà ancestral.

La vocación de la Región Inca debe ser de bilingüismo. Por eso, la escritura de los nombres de las calles, pueblos, comunidades y accidentes geográficos, debería ser en quechua y en castellano. Lo que sí merece una sabia y decorosa rectificación del gobiemo regional es la aceptación del alfabeto oficial del quechua cuyo objetivo es unificar la escritura del quechua de manera que el caos existente actualmente desaparezca o, por lo menos, disminuya. (Véase Cerrón-Palomino, 1992). Ojalá que la Región Mariátegui estudie también medidas de cooficialización del quechua y del castellàno en la zona de habla quechua predominante y de cooficialización del aymara y del castellano en la zona de habla aymara predominante. Y que estas medidas se den dentro de un contexto de adecuada implementación a largo plazo, con el concurso de una ciudadanía que acepta sus raíces y su historia y las enarbola como sustentos de su identidad. 
9.-El Ministerio de Educación publicó en 1989 una Politica de Educación Bilingüe Intercultural. En la presentación se afirma que se opta "por una educación para la Democracia, el Desarrollo y la Cultura, finalidades específicas engarzadas firmemente con el fin básico de la educación peruana: educarnos para rescatar, desarrollar, a finar y dinamizar la conciencia histórica del peruano como persona y como colectividad". La educación bilingüe intercultural es caracterizada como "una modalidad que se da a través de los diferentes niveles del sistema educativo" (p.12). Acorde con esta caracterización, los lineamientos se refieren a la educación inicial, la educación primaria de menores y adultos, la educación secundaria y los centros de formación magisterial y profesionalización docente, lo cual es un decidido reconocimiento del Perú multilingüe y pluricultural. Se establece que en las zonas de uso predominante de una lengua vernácula:1. La lengua matema se utilice comolengua instrumental a nivel oral en educación inicial. 2. La lengua materna constituya una línea de acción educativa independiente paralela al castellano de $1^{\circ}$ a $6^{\circ}$ grados de primaria. 3. "Se procurará ofrecer asignaturas de lenguas vernáculas para fomentar su cultivo y desarrollo en su forma oral y escrita en el nivel secundario". 4. Los centros de formación magisterial y de profesionalización incluirán cursos sobre lenguas vernáculas, fundamentos y tecnología de la educación bilingüe intercultural, etc. 5. "Se propiciará que la educación de los alumnos castellanohablantes desde el nivel inicial hasta la universidad, posibilite el conocimiento, valoración y apropiación crítica de elementos de las diversas culturas peruanas" y se apoyará la enseñanza de lenguas vernáculas como segundo idioma para estas mismas poblaciones hispanohablantes.

En fin, los lineamientos son una admirable y coherente pieza que recoge lo mejor del pensamiento sobre política lingüística, vertido en las décadas 60,70 y 80. Leyendo esta política uno estaría tentado a decir: "Seacabaron las palabras; ahora es el turno de la acción".

10.-Sin embargo, se produjo un cambio ministerial y el Ministerio de Educación, a través de la Dirección General de Educación Bilingüe creada en 1987 y desaparecida ya, publicó una Política Nacional de Educación Intercultural y Educación Bilingüe Intercultural, destinada a orientar el quinquenio 1991-1995. Por el título se puede notar que se ha tratado de distinguir lo que corresponde sólo a las poblaciones de habla vernácula -la política de educación bilingüe intercultural-y lo que corresponde tanto a la población hispanohablante y a la vernáculohablante, o sea, la educación intercultural, convertida en principio rector de todo el sistema educativo peruano. 
La pregunta inmediata que surge es ¿Qué es la interculturalidad? respuesta que ya había abordado sucintamente la política de 1987. En la fundamentación de la política para el quinquenio 1991-95, se describe la interculturalidad como "...el diálogo entre culturas, que a partir de la propia matriz cultural, incorpora selectiva y críticamente elementos culturales provenientes de la cultura occidental y de las otras culturas coexistentes en el país" (p. 6). La apertura a las otras culturas se cimenta en la autoafirmación del individuo como miembro de una cultura determinada. La política lingüística para el quinquenio señala, por primera vez y de manera específica que "La educación nacional debe también aprovechar los aportes culturales de otras comunidades, ahora igualmente peruanas, como son la negra y la asiática, sobrepasando así la concepción dual de la sociedad peruana, constituida por dos segmentos culturales, el indio y el occidental. La actual política lingüística propicia un cambio cualitativo, basado en la comprensión y respeto de los grupos hispanohablantes hacia los grupos autóctonos y viceversa, para lograr lo cual es necesario contar con currículos diversificados que informen y alienten relaciones solidarias interétnicas e interculturales.

Al incluir tanto la educación escolarizada como la no escolarizada, la política tambiên supera críticas anteriores a la concepción de educación bilingüe con la que se ha operado (Véase Escobar et al, 1975:112). Asimismo, supera críticas cuando considera la educación una variable más de desarrollo (Sección 2.2). Otro acierto es el énfasis en la investigación en cuanto sea relevante a la EBI, que es un vacío lamentable en las acciones de política lingüística. Recuerdo que en 1987 (Pozzzi-Escot:28) insistía ya en la necesidad de estudiar los castellanos regionales, lo que a duras penas se ha hecho. Una ausencia en relación al castellano es que la política no hace referencias al bidialectalismo ni a los dialectos estigmatizados, como lo hacía la Política de 1972. Un nuevo énfasis en la escritura de lenguas vernáculas la constituye una sección de la política, en la que se da bastante importancia a la difusión de los alfabetos oficiales de las lenguas vernáculas y de sus manuales de ortografía, con miras a que estas lenguas puedan asumir nuevas funciones más acordes con los contactos crecientes entre los que vivieron predominantemente en el mundo de la oralidad y los que lo hacen inmersos en el mundo de lo escrito y de la imagen. El punto 4.2 establece: "Se fomentará la producción escrita en la lengua vernácula como parte integrante del proceso educativo formal", lo cual puede significar cambios radicales para las zonas donde se implante. La concepción de producción escrita es muy amplia y se tratará que el vernáculohablante tenga acceso a escritos en su lengua, de índole diversa. Veinte años atrás yo preguntaba en el Primer Serninario Nacional de Educación Bilingüe: "¿Para qué sirve aprender a leer 
en una lengua si hay uno o dos textos escritos en esa lengua? (Pozzi-Escot, 1972:51). Ojalá que la voluntad de fomentar la literatura escrita en lengua vernácula se cumpla, así como la elaboración de traducciones del castellano a las lenguas vernáculas y viceversa. Ojalá que la voluntad de lograr una unidad ortográfica pandialectal -en el caso del quechua, por ejemplo,-se concrete en la práctica de la escritura que las escuelas bilingües y los órganos periodísticos de todo tipo generen.

11.-Si revisamos el panorama de los últimos 30 años, desde lo discutido en la mesa Redonda de 1963 hasta hoy, percibimos un indudable progreso en el plano conceptual. En 1963, se trataba de explicar ideas como que enseñar castellano a hablantes de una lengua vernácula es una tarea diferente a enseñar un curso de castellano a un hispanohablante. En 1963, había que distinguir alfabetizar de castellanizar y un pequeñísimo número de personas realmente entendía la distinción. Hoy día las políticas lingüísticas explícitas revelan un buen manejo de información actualizada. El gran déficit está en la difusión y la implementación. Es en esas direcciones hacia donde debe dirigir sus esfuerzos el país entero. No es posible que si hoy se comprende que un niño monolingüe aymara no puede ser educado por un maestro monolingüe hispanohablante, esas condiciones aún se den. No es posible que aún el niño amazónico sea víctima de la deseducación: que a través de la escuela lo alejemos tanto del saber y las prácticas de su pueblo como del conocimiento occidental. Si la Conquista española nos trajo el convencimiento de que "los papeles hablan", ¿por qué no hacemos que realmente hablen, transformándolos en acción? ¿De qué nos sirven las leyes, las constituciones y las "políticas" si no podemos traducirlas en bienestar individual y colectivo? Necesitamos una mente empresarial que ponga en marcha un plan de implementación debidamente financiado que logre que ese CÚMPLASE de cada ley aprobada a favor de nuestra política lingüística, se haga realidad. De otra manera, seguiremos arando en el mar. 
(1). Recalquemos que el catalán es hablado en España por más de 6 millones de hablantes de los territorios de habla catalana; en la Comunidad Autónoma, según el censo de $1986,64 \%$ de la población habla el catalán y $90 \%$ lo entiende. $Y$ dato sumamente revelador: desde que el catalán fue reintroducido obligatoriamente en el sistema educativo y utilizado en radio, televisión y prensa, los jovvenes de 15 a 19 años tienen más altos niveles de competencia en la lengua que sus mayores (New Lang. Planning Newsletter,1992, Vol.6, NN3, p.l.). Para la comparación con el caso peruano del quechua, por ejemplo, notemos que el catalán es una lengua circunscrita en su uso prácticamente a España y el sudeste de Francia. Sin embargo, los catalanes, con la voluntad indeclinable de hacer valer su lengua, siguen aumentando el número de sus hablantes, ensefiando la lengua a los migrantes y a niños y jóvenes, al punto que pudieron darse el gusto supremo de dirigirse al mundo en catalán al inaugurar los juegos olímpicos de 1992 ante el rey de Espafia, hispanohablante. Esta es una lección para nuestros políticos que tan facilmente tiran la esponja y desahucian al quechua (cf. Chirinos Soto, 1984:99).

(2) (3). Un grupo de científicos sociales ha presentado al Congreso Constituyente Democrático la siguiente propuesta substitutoria para los artículos $35^{\circ}$ y $83^{\circ}$ :

Art. $35^{\circ}$ "El Estado garantiza el derecho de los pueblos quechua, aymara y amazónicos a recibir educación bilingüe intercultural sin distinción de niveles. El Estado promueve el estudio y desarrollo de las lenguas de otros pueblos".

Art. $83^{2}$ "El Perú es un país plurilingüe y pluricultural. El castellano es el idioma oficial de la República. El quechua y el aimara son idiomas oficiales regionales. Las lenguas amázonicas podrán ser oficiales en las provincias o distritos donde su uso es predominante". 
Amazonia Peruana

\section{BIBLIOGRAFIA}

CASA DE LA CULTURA DEL PERÚ.

1966 Mesa Redonda sobre el Monolingüismo Quechua y Aymara y la Educación en el Perú. Lima.

CERRÓN-PALOMINO, RODOLFO.

1992 "Sobre el uso del alfabeto oficial quechua-aimará". En El Quechua en Debate, pp,121-155

CHIRINOS SOTO, ENRIQUE.

1984 La nueva constitución al alcance de todos. $3^{\text {ra }}$ edición. Lima, AFA Editores.

ESCOBAR, ALBERTO et al.

1975 Perú, ¿país bilingüe? Perú Problema 13. Lima: Instituto de Estudios Peruanos.

FISHMAN, JOSHUA A. (Editor).

1968 Readings in the sociology \& language. The Hagne: Monton \& C.

FISHMAN, JOSHUA A. (Editor).

1992 Reversing language shift. Clevedon: Multilingual Matters Ltd.

GARVIN, PAUL Y MADELEINE MATHIOT.

1968 "The urbanization \& Guaraní language. A problem in Language and culture". In Fishman (Editor) pp. 365-374

GODENZZI, JUAN CARLOS (Editor).

1992 El quechua en debate. Cuzco: Centro de Estudios Regionales Andinos "Bartolomé de las Casas"

HEISE, MARÍA et al.

1992 Interculturalidad. Un Desafío. Lima: CAAAP.

LOPEZ LUIS ENRIQUE et al.

1989 Temas de lingüística aplicada. Lima: concytec y GTZ. 
LOPEZ LUIS ENRIQUE y RUTH MOYA (Editores).

1989 Pueblos indios, estados y educación. Lima:PEB, Puno, MEC-GTZ, ERA

MINISTERIO DE EDUCACIÓN.

1972 Primer Seminario Nacional de Educación Bilingüe. Algunos estudios y ponencias. Lima

MINISTERIO DE EDUCACIÓN.

1972 Ley General de Educación. Decreto Ley 19326. Lima.

MINISTERIO DE EDUCACIÓN.

1972 Política nacional de educación bilingüe. Lima

MINISTERIO DE EDUCACIÓN.

1989 Política de educación bilingüe intercultural. Lima: 17 pp.

MINISTERIO DE EDUCACIÓN.

s/f Política nacional de educación intercultural y educación bilingüe intercultural. Quinquenio 1991-1995

PLAZA MARTINEZ, PEDRO.

"Verdades y falacias de la política lingüístico-Educativa en Bolivia". En López y Moya (Editores) pp. 45-69

POMA, HUAMÁN.

1990 Nueva crónica y buen gobierno. Selección y prólogo deCarlos Araníbar. Lima: Ediciones Rikchay e Instituto de Apoyo Agrario.

POZZI-ESCOT, INÉS.

1972 "El uso de la lengua vernácula en la educación". En Primer Seminario Nacional de Educación Bilingüe, pp. 43-54.

POZZI-ESCOT, INÉS.

1989 "Reflexiones para una política nacional de lenguas y culturas en la educación". En Temas de linguística aplicada, Lopéz et al, (Editores) pp.21-54.

PROGRAMA INTERAMERICANO DE LINGUÍSTICA Y ENSEÑANZA DE IDIOMAS.

1974 El Simposio de San Juan, Puerto Rico, junio de 1971. 
RAY, PUNYA SLOKA.

1968 "Language standardization". En Fishman (Editor) pp. 754-765.

RUBIN, JOAN y BJÖRN H. JERNUDD (Editors)

1971 Can language be planned? sociolinguistic theory and practices for developing nations. Hawaii: The University Press of Hawaii.

RUBIN, JOAN y ROGER SHUY (Editors)

1973 Language planning: current issues and research. Washington: Georgetown University Press.

RUBIO, MARCIAL y ENRIQUE BERNALES.

1983 Constitución y sociedad política. Lima: Mesa Redonda Editores.

- SAVILLE, MURIEL y RUDOLPH C. TROIKE.

1971 A handbook \& bilingual education. Revised edition. Washington, D.C., TESO

SOLÁ. DONALD F.

1974 "Tipología de la política lingüística". En Simposio de San Juan, Puerto Rico, pp. 6-15

VON GLEICH, UTTA y EKKCHARD WOLFF (Editors)

1991 Standardization of national language. Symposium on Language Standardization. Hamburgo.

WEBB, RICHARD y GRACIELA FERNANDEZ BAZA.

1991 Perú en números 1991. Anuario estadístico. Lima: Cuanto S.A.

WOLFF, EKKCHARD. "Standardization and varieties of written Haunsa (West Africa)". En: von Gleich y Wolff, (Editors), pp 21-31. 